Journal of Pharmaceutical Sciences Volume 96, Issue 1, Pages 27-37

Copyright (C) 2007 Wiley-Liss, Inc., A Wiley Company

\title{
Biowaiver monographs for immediate release solid oral dosage forms: Prednisolone
}

\author{
M. Vogt 1, H. Derendorf 2, J. Krämer 3, H.E. Junginger 4, K.K. Midha 5, V.P. Shah 6, S. \\ Stavchansky 7, J.B. Dressman 1, D.M. Barends 8 *
}

1Department of Pharmaceutical Technology, Johann Wolfgang Goethe University, Frankfurt am Main, Germany

2College of Pharmacy, University of Florida, Gainesville, Florida

3Phast GmbH, Homburg/Saar, Germany

4Naresuan University, Faculty of Pharmaceutical Sciences, Phitsanulok, Thailand

5University of Saskatchewan, Saskatoon, Saskatchewan, Canada

6International Pharmaceutical Federation FIP, Den Haag, The Netherlands

7Division of Pharmaceutics, College of Pharmacy, University of Texas at Austin, Austin, Texas

8RIVM - National Institute for Public Health and the Environment, Bilthoven, The Netherlands

${ }^{*}$ Correspondence to D.M. Barends, RIVM - National Institute for Public Health and the Environment, Bilthoven, The Netherlands. Telelephone: +31 30 2744209; Fax: +31 30 2744462 Dirk.Barends@RIVM.nl

A project of the International Pharmaceutical Federation FIP, Groupe BCS, www.fip.org. This article reflects the scientific opinion of the authors and not the policies of regulating agencies.

\begin{abstract}
Literature data relevant to the decision to allow a waiver of in vivo bioequivalence (BE) testing for the approval of immediate release (IR) solid oral dosage forms containing prednisolone are reviewed. Data on its solubility, oral absorption, and permeability are not totally conclusive, but strongly suggest a BCS Class 1 classification. Prednisolone's therapeutic indications and therapeutic index, pharmacokinetics, and the possibility of excipient interactions were also taken into consideration. Available evidence indicates that a biowaiver for IR solid oral dosage forms formulated with the excipients tabulated in this article would be unlikely to expose patients to undue risks.
\end{abstract}

\section{INTRODUCTION}

A monograph based on literature data is presented on prednisolone with respect to its biopharmaceutical properties and the risk of waiving in vivo bioequivalence (BE) testing for the approval of new and/or reformulated immediate release (IR) solid oral dosage forms. The purpose and scope of these monographs has been discussed previously.[1] Briefly, the aim of these monographs is to evaluate all pertinent data available from literature sources for active pharmaceutical ingredients (APIs) on the WHO List of Essential Medicines,[2] to assess the appropriateness of such a biowaiver from the biopharmaceutical point of view and also from the perspective of public health. This systematic approach to recommend or advise against a biowaiver decision is referred to in the recently published WHO Guideline[3] stating that these monographs provide detailed information which should be taken into account whenever available in the biowaiver consideration. Monographs have already been published on acetaminophen (paracetamol),[4] amitriptyline,[5] atenolol,[1] chloroquine,[6] cimetidine,[7] ibuprofen,[8] propranolol,[1] ranitidine,[9] and verapamil.[1]

\section{EXPERIMENTAL}

Published information was obtained from PubMed, up to October 2005, and through the International Pharmaceutical Abstracts. Key words used were: prednisolone, prednisone, 
corticosteroids, indication, solubility, polymorphism, partition coefficient, permeability, absorption, distribution, metabolism, excretion, dissolution, and excipients.

\section{GENERAL CHARACTERISTICS}

Prednisolone (INN) is a synthetic steroid that is chemically defined as $11,17,21$ trihydroxypregna-1,4-diene-3,20-dione. Its structure is shown in Figure 1.<smiles>C[C@]12C=CC(=O)C=C1CC[C@H]1[C@@H]3[C@@H](O)C[C@]4(C)[C@H](C(=O)CO)[C@@]4(O)CC[C@@H]3[C@@H]12</smiles>

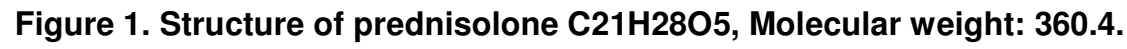

Therapeutic Indication, Dose, and Therapeutic Index

Prednisolone is a well-known corticosteroid that is used to treat a wide variety of acute and chronic disorders, including arthritis, asthma, allergic diseases, hepatitis, congenital adrenal hyperplasia, systemic lupus erythematosus and certain haematological, infectious, cardiac, dermal, neurological, metabolic, gastrointestinal (GI) diseases as well as malignant diseases and many inflammatory states.[10-14] Furthermore, prednisolone is used intravenously at very high doses for the treatment of severe shock.[14]

Prednisolone is used over a wide dose range. Low dose corticosteroid therapy is considered to include doses up to $10 \mathrm{mg}$ prednisolone per day, being most commonly prescribed at approximately $5-7.5 \mathrm{mg} / \mathrm{day}$. The dosage must be individualized and is highly variable depending on the nature and severity of the disease, and on patient response. There is no absolute maximum dosage, however, intensity and frequency of adverse events is observed to rise with increasing dose. Prednisolone is not considered to be a narrow therapeutic index drug and there is generally no need to monitor blood levels. However, for severe diseases that require very high doses of prednisolone, a monitoring of blood levels may be advisable.[14]

A special consideration that should be given in prednisolone therapy is to follow appropriate procedures for withdrawing chronically treated patients from high doses of the drug. The strategy to withdraw the patient from systemic corticosteroids depends on the period of treatment and the likelihood of the disease to relapse. In patients who have received systemic corticosteroids for more than 3 weeks at high doses, withdrawal should be gradual[14],[15] in order to allow the hypothalamo-pituitary-adrenal (HPA) axis to recover. Abrupt withdrawal of systemic corticosteroid treatment which has continued for up to 3 weeks may be appropriate if the disease is unlikely to relapse[16],[17] and is unlikely to lead to clinically relevant HPA-axis suppression.[18] In cases where a dose tapering schedule is appropriate, up to date recommendations can be found in the recent literature.[14] Low dose corticosteroid therapy can generally be terminated without dose tapering although a gradual withdrawal is often recommended.

\section{PHYSICO-CHEMICAL PROPERTIES}

\section{Esters and Salts}

Several esters of prednisolone are available. Apart from prednisolone itself, the USP 28 includes prednisolone acetate, prednisolone hemisuccinate, prednisolone sodium phosphate, prednisolone sodium succinate, and prednisolone tebutate,[19] while the EP 5th edition monographs prednisolone acetate, prednisolone pivalate, and prednisolone sodium 
phosphate.[20] Ester compounds currently having a marketing authorization (MA) in Germany (DE) are prednisolone hydrogen succinate, prednisolone sodium phosphate, and prednisolone acetate.[12] This monograph pertains to prednisolone itself, but not to ester forms.

\section{Polymorphism}

Prednisolone exhibits polymorphism.[20] Two forms have been characterized.[21],[22] Prednisolone also forms solvates with water and chloroform (pseudo-polymorphism).[19],[22] USP 28 monographs both the anhydrous form and the sesquihydrate.[19] This monograph pertains both to prednisolone anhydrous and the sesquihydrate.

\section{Solubility}

Prednisolone is very slightly soluble in water (1 g dissolves in 1000-10000 mL).[20] An aqueous solubility ranging from 0.22 to $0.24 \mathrm{mg} / \mathrm{mL}$ has been reported (without indicating the temperature),[23],[24] which is in accordance with a value of $243 \mu \mathrm{g} / \mathrm{mL}$ that was measured at $25^{\circ} \mathrm{C}$.[25] Table 1 summarizes solubility data available in the literature, together with the corresponding dose:solubility ratio. The WHO maximum dose strength is $5 \mathrm{mg}$.

Table 1. Solubility $(\mathrm{mg} / \mathrm{mL})$ of Prednisolone at $25^{\circ} \mathrm{C}[25]$ and Dose: Solubility Ratios $(D / S)(m L)$ for Four Strengths Covering the Extremes of the Range

\begin{tabular}{llllll} 
Medium & Solubility & $\mathbf{D} / \mathbf{S}(\mathbf{1} \mathbf{~ m g})$ & $\mathbf{D} / \mathbf{S}(\mathbf{5} \mathbf{~ m g})$ & $\mathbf{D} / \mathbf{S}(\mathbf{1 0} \mathbf{~ m g})$ & $\mathbf{D} / \mathbf{S}(\mathbf{5 0} \mathbf{~ m g})$ \\
\hline Water & $0.243 \mathrm{mg} / \mathrm{mL}$ & $4.1 \mathrm{~mL}$ & $21 \mathrm{~mL}$ & $41 \mathrm{~mL}$ & $206 \mathrm{~mL}$
\end{tabular}

Five milligrams reflects the WHO maximum dose strength. The critical limit for $\mathrm{D} / \mathrm{S}$ at $37^{\circ} \mathrm{C}$ is $<250 \mathrm{~mL}$.[3],[72-74]

\section{Partition Coefficient}

LogP values of 1.59 and 1.62 have been reported.[23],[26],[27] Calculated values obtained by different methods range from 1.38 to $1.49[27],[28]$ and from 2.5 to 3.5.[29]

\section{pKa}

The chemical structure of prednisolone (see Fig. 1) does not provide any acid or basic elements, and hence is a neutral substance and no reference to a pKa value was found in the literature.

\section{Dosage Form Strength}

Strengths of IR solid oral dosage forms with a current MA in DE are 1, 2, 2.5, 5, 10, 20, and $50 \mathrm{mg}$, in Finland (FI) 5, 20, and $40 \mathrm{mg}$ and in The Netherlands (NL) 5, 20, 30, and $50 \mathrm{mg}$, see Table 2. 
Table 2. Excipients ${ }^{\star}$ Present in Prednisolon IR Solid Oral Drug Products with a Marketing Authorization (MA) in Germany (DE), Finland (FI), and The Netherlands (NL), and the Minimal and Maximal Amount of That Excipient Present Pro Dosage Unit in Solid Oral Drug Products with a MA in the USA

\begin{tabular}{|c|c|c|}
\hline Excipient & $\begin{array}{l}\text { Drug Products Containing That Excipient with } \\
\text { a MA Granted by the Named Country }\end{array}$ & $\begin{array}{l}\text { Range Present in Solid Oral Dosage } \\
\text { Forms with a MA in the USA (mg) }\end{array}$ \\
\hline Calcium stearate & $\mathrm{FI}(1)$ & $0.7-43^{\mathrm{a}}$ \\
\hline Castor oil hydrogenated & $\mathrm{Fl}(1)$ & $0.93-37.6^{\mathrm{a}}$ \\
\hline Cellulose & $\mathrm{DE}(2-5) \mathrm{FI}(1,6,7) \mathrm{NL}(8)$ & $4.6-1385^{\mathrm{a}}$ \\
\hline Copovidone & $\mathrm{FI}(1)$ & $86-500$ \\
\hline Croscarmellose sodium & $\mathrm{DE}(3) \mathrm{FI}(6,7)$ & $2-180$ \\
\hline Crospovidone & $\mathrm{FI}(1)$ & $4.4-792^{\mathrm{a}}$ \\
\hline Gelatin & $\mathrm{DE}(9)$ & $1-756^{\mathrm{a}}$ \\
\hline Hydroxypropylcellulose & $\mathrm{DE}(10)$ & $1-132$ \\
\hline Hypromellose & $\mathrm{DE}(2,3,11,12)$ & $0.8-80$ \\
\hline Lactose & $\mathrm{DE}(2-5,9-22) \mathrm{FI}(1) \mathrm{NL}(8,23-28)$ & $23-1020^{a}$ \\
\hline Magnesium stearate & $\mathrm{DE}(2-5,9-22) \mathrm{FI}(6,7) \mathrm{NL}(8,23-28)$ & $0.9-401^{a}$ \\
\hline Maize starch & $\mathrm{DE}(2-5,11,12) \mathrm{NL}(28)$ & $9.9-1135^{\mathrm{a}}$ \\
\hline Mannitol & $\mathrm{FI}(6,7)$ & $10-454$ \\
\hline Potato starch & $\mathrm{DE}(9,13,14,16-18,20-22) \mathrm{NL}(23-27)$ & $2.1-80$ \\
\hline $\begin{array}{l}\text { Potato starch } \\
\text { (pregelatinized) }\end{array}$ & $\mathrm{NL}(23-25,27)$ & \\
\hline Povidone & $\mathrm{FI}(6,7) \mathrm{NL}(8,26)$ & $0.17-75$ \\
\hline Silica & $\mathrm{DE}(2-5,10-14,16-18,20-22) \mathrm{FI}(1,6,7) \mathrm{NL}(23-27)$ & $0.65-99$ \\
\hline Sodium lauryl sulfate & $\mathrm{DE}(5)$ & $0.65-50$ \\
\hline Sodium starch glycolate & $\mathrm{DE}(2,9-22) \mathrm{NL}(8,23-25,27,28)$ & $2-876^{\mathrm{a}}$ \\
\hline Starch, pregelatinized & $\mathrm{NL}(28)$ & $6.6-600$ \\
\hline Talc & $\mathrm{DE}(2,9,11,12) \mathrm{FI}(1) \mathrm{NL}(8,26)$ & $0.1-220^{\mathrm{a}}$ \\
\hline
\end{tabular}

Sources of data: DE: www.rote-liste.de (April 4, 2006); Fl: www.nam.fi (April 5,2006); NL: www.cbg-meb.nl. (April 3, 2006). USA: http://www.fda.gov/cder/iig/iigfaqWEB.htm\#purpose (IIGQInte.txt version date 02-02-2006).

* Colorants, flavors, and ingredients present in printing ink only are not included.

a The upper range value reported is unusual high for IR solid oral dosage forms and the authors doubt its correctness.

1 PREDNISOLON $5 \mathrm{mg}$.

2 Decortin® H 1 mg.

3 Prednisolon $20 \mathrm{mg} /-50 \mathrm{mg}$ JENAPHARM®.

4 Prednisolon-ratiopharm ${ }^{\circledR} 5 \mathrm{mg}$ Tabletten.

5 Prednisolon-ratiopharm $\AA 50 \mathrm{mg}$ Tabletten.

6 PREDNISOLON $40 \mathrm{mg}$.

7 PREDNISOLON $20 \mathrm{mg}$.

8 Prednisolon $30 \mathrm{mg}$, tabletten.

9 Prednisolon $1 \mathrm{mg} /-5 \mathrm{mg}$ JENAPHARM®.

10 Prednisolon $2 \mathrm{mg}$ GALEN@.

11 Decortin ${ }^{\circ} \mathrm{H} 5 \mathrm{mg} /-20 \mathrm{mg} /-50 \mathrm{mg}$.

12 Duraprednisolon $5 \mathrm{mg}$.

13 Decortin $\AA$ H $10 \mathrm{mg}$.

14 Dermosolon $5 \mathrm{mg} /-10 \mathrm{mg} /-20 \mathrm{mg} /-50 \mathrm{mg}$.

15 Hefasolon $\AA$.

16 PredniHEXAL® $5 \mathrm{mg} /-10 \mathrm{mg} /-20 \mathrm{mg} /-50 \mathrm{mg}$ Tabletten.

17 Predni H Tablinen $\AA 5 \mathrm{mg} /-50 \mathrm{mg}$.

18 Predni $\mathrm{H}$ Tablinen® $20 \mathrm{mg}$.

19 Prednisolon 2,5/-5-Rotexmedica.

20 Prednisolon $5 \mathrm{mg} /-20 \mathrm{mg} /-50 \mathrm{mg}$ GALEN®.

21 Prednisolon acis $\AA_{5} 5 \mathrm{mg} /-10 \mathrm{mg} /-20 \mathrm{mg} /-50 \mathrm{mg}$.

22 Prednisolon AL 5 mg/-10 mg/-20 mg/-50 mg Tabletten. 
23 Prednisolon $20 \mathrm{PCH}$, tabletten $20 \mathrm{mg}$.

24 Prednisolon $30 \mathrm{mg} \mathrm{PCH}$, tabletten.

25 Prednisolon $50 \mathrm{PCH}$, tabletten $50 \mathrm{mg}$.

26 Prednisolon CF $5 \mathrm{mg}$, tabletten.

27 Prednisolon $5 \mathrm{PCH}$, tabletten $5 \mathrm{mg}$.

28 Prednisolon ratiopharm $5 \mathrm{mg}$, tabletten.

\section{PHARMACOKINETIC PROPERTIES}

\section{Absorption and Bioavailability (BA)}

Following oral intake prednisolone is rapidly absorbed from the Gl tract. The systemic availability is almost complete and reported to range from $75 \%$ to $98 \%,[11],[14],[30-39]$ with a concentration-time profile that is very similar to that when prednisone is taken orally.[40],[41] Maximum serum concentrations occur within 1-2 $\mathrm{h}$ after administration of a single dose.[10],[11],[14],[31],[32],[35],[42-44] Food intake prolongs the time to peak concentration, but does not affect the extent of absorption.[45-47] No indication of existence of an absorption window was found in the literature.

\section{Permeability}

An apparent permeability coefficient of $2 \times 10-5 \mathrm{~cm} / \mathrm{s}$ was measured in Caco-2 cells.[28] Using artificial phospholipid membranes, a value of $0.2 \times 10-6 \mathrm{~cm} / \mathrm{s}$ was reported.[48]

\section{Distribution}

The volume of distribution of prednisolone was reported as $0.22-0.70$ L/kg.[31],[44],[49] With increasing dose, the volume of distribution of prednisolone increases, due to a shift in a larger fraction of the body burden from the plasma compartment to other body tissues or to sites of greater metabolic activity.[44] The concentration-dependent binding of prednisolone to the plasma proteins (i.e., transcortin and albumin) results in the dose-dependent nonlinear pharmacokinetics observed for prednisolone.[11],[50],[51] Transcortin has high affinity and low capacity binding sites while albumin has low affinity and a high capacity for binding prednisolone. The fraction bound is not constant and decreases in a nonlinear fashion with increasing concentrations: at low concentrations protein binding appears to be quite high (80\%-90\%), but declines at higher prednisolone levels to 60\%-70\%.[33],[44],[49],[50],[52] For plasma concentrations of up to $400 \mathrm{ng} / \mathrm{mL}$ an approximate linear function of fraction bound can be assumed, which switches over to a constant (lower) relation above $600 \mathrm{ng} / \mathrm{mL}$,[44] reflecting the saturable binding of prednisolone to transcortin. Binding of prednisolone to plasma protein is independent of the route of administration.[51]

Distribution and elimination of prednisolone have been described in terms of a twocompartment open model, with rapid distribution within the first half-hour followed by a slower terminal elimination phase.[11],[36]

Prednisolone is able to penetrate the blood-brain barrier, reaching about $1 / 10$ of the serum concentration in cerebrospinal fluid. Like all glucocorticosteroids, prednisolone crosses the placenta.[14],[53] The use of prednisolone is usually compatible with breast feeding[54] since its concentrations in breast milk are minimal ( $<10 \%$ of serum level) and represents a negligible addition to the infants endogenous cortisol production.[55]

\footnotetext{
Metabolism and Excretion

Prednisolone is pharmacologically active and may be metabolized in a variety of tissues, including liver, lung, kidney, and skin.[14],[56],[57] Prednisolone is partially converted into prednisone, which is inactive. Both steroids undergo a reversible and dose-dependent metabolism. The interconversion equilibrium strongly favors the formation of prednisolone,[11],[40] resulting in a ratio of prednisolone to prednisone plasma concentrations of $4: 1$ to $10: 1 .[44],[58]$ The nonlinear interconversion varies with time and dose.[11],[31],[44],[49],[59-62] The serum half-life of prednisolone is known to be 2-4 $\mathrm{h},[10],[11],[32],[33],[39],[44],[46]$ and may be influenced by time of day, age, gender, physical exercise, pregnancy, drugs, and several diseases.[14]
} 
Prednisolone is cleared from the body primarily by hepatic metabolism by hydroxylation and reduction forming metabolites which conjugate with glucuronic acid and sulfate.[11],[63] The most important unconjugated metabolite is 6-hydroxyprednisolone. Eleven metabolites of prednisolone and prednisone have been identified.[51] Certain metabolites were found in both the unconjugated and the conjugated forms in the urine, the percentage in the unconjugated being about twice as large as that in the conjugated. An appreciable proportion, $11 \%-24 \%$ of a given dose of prednisolone, can be recovered in urine unchanged. Approximately $2 \%-5 \%$ is excreted in the urine as prednisone.[44]

The clearance of prednisolone is dose-dependent,[31-33],[44],[59],[60,64] due to the concentration-dependent protein binding, that is, at high doses the increased free fraction of prednisolone is reflected in a greater plasma clearance and apparent volume of distribution. The total body clearance of prednisolone has been reported to be $111 \mathrm{~mL} / \mathrm{min} / 1.73 \mathrm{~m} 2$ for a 5 $\mathrm{mg}$ dose and $194 \mathrm{~mL} / \mathrm{min} / 1.73 \mathrm{~m} 2$ for a $40 \mathrm{mg}$ dose of prednisolone.[35],[44]

Renal elimination comprises $40 \%$ of total elimination.[65] The mean elimination half-life increases with the dose and ranges from 2.1 to $3.5 \mathrm{~h}$.[11],[33],[66] The half-life in children is shorter than that recorded in most adult studies.[11] Children show no evidence of an abnormal prednisolone metabolism. Women appear to have a slightly higher clearance of prednisolone (around 18\% higher)[67] and excrete significantly more 6-hydroxyprednisolone than men[51] - in step with the finding that estrogens enhance the hydroxylation of cortisol.

\section{DOSAGE FORM PERFORMANCE}

\section{Excipients and/or Manufacturing Variations}

A wide range of excipients has been used in several formulations of IR prednisolone tablet products approved for marketing in DE, where the market leader is Decortin ${ }^{\circledR} \mathrm{H}$. Table 2 shows the excipients used in IR prednisolone tablets with a MA in DE, FI, and NL. In view of these MAs, it is reasonable to expect that these formulations successfully passed an in vivo BE study. Indeed, a number of Summaries of Product Characteristics (SmPCs) with an MA in $D E$ report results of successful in vivo BE studies.[68-70] Also, in view of the actual clinical use, it can be supposed that the excipients present in a large number of these drug products do not have a significant effect on the extent and rate of absorption of prednisolone, and hence no impact on its clinical use. One product from the German market contains sodium lauryl sulfate (Prednisolon-ratiopharm ${ }^{\circledR} 50$ ). It is highly likely that the surfactant is included in order to ensure an appropriate dissolution rate of the drug. However, the SmPC of this $50 \mathrm{mg}$ product containing sodium lauryl sulfate reports data showing in vivo $B E$ to a reference product, at least with respect to the AUC.[69] Numerous other $50 \mathrm{mg}$ products do not contain any surfactant and are not inferior concerning the rate and extent of absorption. In an aqueous medium at $37.5^{\circ} \mathrm{C}$, magnesium trisilicate seems to adsorb prednisolone and the presence of magnesium oxide leading to chemical degradation.[71] However, these excipients are not part of any formulation currently on the market in the above-mentioned countries and the clinical relevance of the adsorption has never been demonstrated. By contrast, aluminum hydroxide, calcium carbonate, and magnesium carbonate do not seem to adsorb prednisolone.

\section{In Vivo Bioequivalence Studies}

Several studies have demonstrated $B E$ in vivo among specific marketed prednisolone products.[14] In a randomized crossover study in 13 healthy volunteers, prednisolone tablet formulations of 2,5 , and $20 \mathrm{mg}$ were found to be bioequivalent in vivo to a reference if the same dosage was administered.[39] Two studies designed as four-treatment crossover evaluations in 12 adult male volunteers found seven different commercially available prednisolone tablets bioequivalent in vivo; these products demonstrated in vitro dissolution of at least $75 \%$ in $30 \mathrm{~min}$.[43]

\section{Dissolution and In Vitro/In Vivo Correlation}

The USP 28 specification for dissolution of prednisolone tablets is not less than $70 \%(\mathrm{Q})$ dissolved in $30 \mathrm{~min}$ in $900 \mathrm{~mL}$ water, using the paddle at $50 \mathrm{rpm}$.[19] Prednisolone became official in USP 15 (Second Supplement, April 1959), and the monograph was extended by the content uniformity requirement in USP 17 . USP 18 included a dissolution test in which $60 \%$ of 
Journal of Pharmaceutical Sciences Volume 96, Issue 1, Pages 27-37

the labeled amount of prednisolone was required to dissolve in de-aerated water in not more than $20 \mathrm{~min}$. In vitro/in vivo correlations were not found in the literature.

\section{DISCUSSION}

\section{Solubility}

Solubility criteria defined in present regulatory guidances[3],[72-74] for classifying an API as highly soluble requires the highest dose strength to be soluble in $250 \mathrm{~mL}$ of water over the $\mathrm{pH}$ range of $1-7.5$ at $37^{\circ} \mathrm{C}$. The available data therefore do not provide all information necessary for $\mathrm{BCS}$ classification. Although solubility over this $\mathrm{pH}$ range can be assumed to be independent of $\mathrm{pH}$ (nonionizable drug), literature results were determined at $25^{\circ} \mathrm{C}$ rather than $37^{\circ} \mathrm{C}$. At $25^{\circ} \mathrm{C}$, prednisolone meets already the dose:solubility ratio criterion of below $250 \mathrm{~mL}$, that is, is highly soluble.[3],[72-74] It is reasonable to assume that prednisolone has an endothermic heat of solution and that the solubility at $37^{\circ} \mathrm{C}$ will be even higher.

\section{Permeability}

Numerous studies report averages of $80 \%-100 \%$ for the systemic availability of prednisolone following oral administration. Only very limited in vitro studies on the permeability of prednisolone could be located. One result, reporting a permeability of $0.2 \times 10-6 \mathrm{~cm} / \mathrm{s}$, used artificial phospholipid membranes. Using the same system, for metoprolol a log permeability of about -5.2 was reported,[48] corresponding to $6.3 \times 10-6 \mathrm{~cm} / \mathrm{s}$, suggesting the permeability of prednisolone to be slightly lower than the permeability of metoprolol, a substance often taken as reference for the criterion highly permeable drug substance.[29] Also, the logP of prednisolone seems to be slightly below the logP of metoprolol.[29] On the other hand, in Caco-2 cells, a permeability of $2 \times 10-5 \mathrm{~cm} / \mathrm{s}$ was reported,[28] and using the same system, for verapamil an apparent permeability of $1.5 \times 10-5 \mathrm{~cm} / \mathrm{s}$ was reported. As verapamil is assumed to be highly permeable,[1] prednisolone can thus be assumed as highly permeable as well.

The FDA and also the EMEA Guidance[73] define highly permeable as having a fraction dose absorbed of not less than $90 \%$. The recently adopted WHO Guidelines set a limit of not less than $85 \%$ of the fraction dose absorbed.[3],[74]

Taking all available evidence into consideration, the data set is not fully conclusive, but suggests strongly prednisolone to be highly permeable or very close to highly permeable, depending on the criterion set.

Prednisolone has nonlinear pharmacokinetics, which sometimes are seem as a caveat to a positive biowaiver decision.[73] Generally speaking, nonlinear pharmacokinetics has little relevance to equivalence testing, either in vivo or in vitro, since the test product will have the same dose as the reference product. Moreover, most reported in vivo studies include also higher doses, for example, $20 \mathrm{mg}$, indicating also that any nonlinear pharmacokinetics is not relevant for the biowaiver decision over the full range of tablet strengths.

\section{BCS Classification}

Kasim et al.[29] classified prednisolone as BCS Class 1. However, their classification is based on correlations of partition coefficients with permeability and such correlations have only limited predictability. For instance, the correlation of $\log P$ with permeability resulted in 8 false negatives from 25 predictions and the correlation of $\mathrm{Clog} P \AA$ with permeability resulted in 8 false negatives and 1 false positive from 28 predictions. Moreover, their correlations are based on calculated partition coefficients, not on experimentally measured partition coefficients. Lindenberg et al.[75] also classified prednisolone as BCS Class 1. The recently adopted revised WHO Guideline classifies prednisolone as BCS Class 1.[3] Wu et al.,[76] using the disposition characteristics of the drug for BCS classification, assigned prednisolone to BCS Class 1 as well. Indeed, data on solubility, oral absorption, and permeability are not totally conclusive, but suggest strongly a BCS Class 1 classification. The lack of reported in vitro/in vivo correlations is consistent with that classification.[77] 
Risks for Bioinequivalence and Surrogate Techniques for In Vivo BE Testing What is the risk that bioinequivalent products could be approved if the biowaiver is applied? Prednisolone is highly soluble according to the present regulatory guidances.[3],[72-74] So, the solubility is not critical and hence the risk of bioinequivalence caused by a difference in dissolution in vivo will be very small if the test formulation meets the criteria for in vitro dissolution profile similarity to the reference formulation, according to these guidances. In principal, bioinequivalence could also be caused by a difference in Gl absorption, resulting from differences in composition between the test formulation and the reference formulation with respect to the excipients. However, prednisolone is on the borderline of highly permeable according to the present regulatory guidances[3],[72-74] and so its Gl absorption is not critical. Hence, the risk of bioinequivalence caused by a difference in permeability will be very small. Furthermore, a wide variety of excipients (Table 2) has been used to formulate prednisolone IR drug products, having a MA in a number of countries, suggesting that the fraction absorbed is not crucially influenced by these excipients.

\section{Risk of Bioinequivalence to the Patient}

Four possible situations could be envisaged resulting from a false biowaiver decision, that is, declaring a test formulation bioequivalent to the reference formulation, whereas this test formulation would be declared bioinequivalent when subjected to an in vivo BE study. The test formulation may give rise to a lower or to a higher AUC and/or to a lower or to a higher Cmax than the reference product.

In the first instance, the test formulation has a lower AUC than that of the reference product and thus might be clinically less effective. This would have serious clinical consequence only in severe, life-threatening diseases that require acute treatment. But such situations require high doses, by parenteral administration, that is, such a therapeutic use is highly unlikely with oral prednisolone products, especially in the dose range listed by the WHO. A further safeguard is that, since prednisolone is a prescription-only drug, therapy will be under periodic review by the physician who can adjust the dose or substitute the product if necessary. The second situation in which a false biowaiver decision would be clinically relevant is when the drug formulation is superbioavailable, that is, the test formulation has a higher AUC than the reference. In this situation, the broad therapeutic index of prednisolone would protect the patient from very serious side effects, as no serious side effects have been observed with this API, even at exceptionally high (acute) doses and serum levels.

Lastly, bioinequivalence caused by a difference in Cmax between the test formulation and the reference formulation would have few clinical implications in view of the therapeutic use of prednisolone IR tablets, being usually prescribed for patients with chronic diseases.

So, all considerations taken together, there is no reason to classify prednisolone as a Narrow Therapeutic Range Drug, which would exclude it from biowaiving according to the FDA and EMEA regulation.[72],[73] Also, the requirement of the recently adopted WHO Guideline is fulfilled, stating only if the risk of an incorrect biowaiver decision and an evaluation of the consequences (of an incorrect, biowaiver-based equivalence decision) in terms of public health and risks to individual patients is outweighed by the potential benefits accrued from the biowaiver approach may the biowaiver procedure be applied.[74]

\section{CONCLUSION}

Data on solubility, oral absorption, and permeability are not totally conclusive, but strongly suggest a BCS Class 1 classification for prednisolone. A false biowaiver decision is highly unlikely to be reached if the test product fulfills the criteria of dissolution profile similarity in three media according to the Guidances.[3],[72-74] A false biowaiver decision is even more unlikely if the test product is formulated with the excipients shown in Table 2, in amounts usually present in IR solid oral dosage forms. Furthermore, even in the very unlikely situation that an incorrect biowaiver decision would be reached, this would not put the patient at undue risk. So, when the conditions-mentioned above are all fulfilled, a biowaiver can be recommended. 
Journal of Pharmaceutical Sciences Volume 96, Issue 1, Pages 27-37

This conclusion is in line with the recommendation given by the WHO for biowaiving of prednisolone,[3] but is more explicit with respect to the excipients that are acceptable for a positive biowaiver decision.

\section{Acknowledgements}

Kik Groot, RIVM, is acknowledged for tabulating the excipient information.

\section{References}

1 Vogelpoel H, Welink J, Amidon GL, Junginger HE, Midha KK, Möller H, Olling M, Shah VP, Barends DM. 2004. Biowaiver monographs for immediate release solid oral dosage forms based on Biopharmaceutics Classification System (BCS) literature data: Verapamil hydrochloride, propranolol hydrochloride, and atenolol. J Pharm Sci 93: 1945-1956. Links

2 WHO. 2005. Model list of essential medicines, 14th edition. Available from URL http://whqlibdoc.who.int/hq/2005/a87017_eng.pdf

3 WHO. 2006. Proposal to waive in vivo bioequivalence requirements for WHO Model List of Essential Medicines immediate-release, solid oral dosage forms. Technical Report Series, No 937, 40th Report, Annex 8 of WHO Expert committee on specifications for pharmaceutical preparations. Available from URL http://whqlibdoc.who.int/trs/WHO_TRS_937_eng.pdf.

4 Kalantzi L, Reppas C, Dressman JB, Amidon G, Junginger HE, Midha KK, Shah VP, Stavchansky SA, Barends DM. 2006. Biowaiver monographs for immediate release solid oral dosage forms: Acetaminophen (Paracetamol). J Pharm Sci 95: 4-14. Links

5 Manzo HR, Olivera ME, Amidon GL, Dressman JB, Barends DM. 2006. Biowaiver monographs for immediate release solid oral dosage forms: Amitriptyline hydrochloride. J Pharm Sci 95: 966-973. Links

6 Verbeeck RK, Junginger HE, Midha KK, Shah VP, Barends DM. 2005. Biowaiver monographs for immediate release solid oral dosage forms based on biopharmaceutics classification system (BCS) literature data: Chloroquine phosphate, chloroquine sulfate and chloroquine hydrochloride. J Pharm Sci 94: 1389-1395. Links

7 Jantratid E, Prakongpan S, Dressman JB, Amidon GL, Junginger HE, Midka KK, Barends DM. 2006. Biowaiver monographs for immediate release solid oral dosage forms: Cimetidine. J Pharm Sci 95: 974-984. Links

8 Potthast H, Dressman JB, Junginger HE, Midha KK, Oeser H, Shah VP, Vogelpoel H, Barends DM. 2005. Biowaiver monographs for immediate release solid oral dosage forms: Ibuprofen. J Pharm Sci 94: 2121-2131. Links

9 Kortejärvi H, Yliperttula M, Dressman JB, Junginger HE, Midha KK, Shah VP, Barends DM. 2005. Biowaiver monographs for immediate release solid oral dosage forms: Ranitidine hydrochloride. J Pharm Sci 94: 1617-1625. Links

10 Francisco GE, Honigberg IL, Stewart JT, et al. 1984. In vitro and in vivo bioequivalence of commercial prednisone tablets. Biopharm Drug Dispos 5: 335-344. Links

11 Pickup ME. 1979. Clinical pharmacokinetics of prednisone and prednisolone. Clin Pharmacokin 4: 111-128. Links

12 Rote Liste. 2004 Online. Häßner K, editor. Frankfurt, Germany: Rote Liste Service GmbH, Available from URL www.rote-liste.de

13 Fachinformation DH. 2002. Bundesverband der Pharmazeutischen Industrie Service GmbH, Aulendorf, Germany.

14 Kaiser H, Kley HK. 2002. Cortisontherapie. Corticoide in Klinik und Praxis. 11. Auflage. Georg Thieme Verlag, Stuttgart, Germany.

15 Salem M, Tainsh RE, Jr., Bromberg J, Loriaux DL, Chernow B. 1994. Perioperative glucocorticoid coverage. A reasessment 42 years after emergence of a problem. Ann Surg 219: 416-425. Links

16 O'Driscoll BR, Kalra S, Wilson M, Pickering CA, Carroll KB, Woodcock AA. 1993. Double-blind trial of steroid tapering in acute asthma. Lancet 341: 324-327. Links

17 Hatton MQF, Vathenen AS, Allen MJ, Davies S, Cooke NJ. 1995. A comparison of abruptly stopping with tailing off oral corticosteroids in acute asthma. Respir Med 89: 101-104. Links 
18 Wenning GK, Wietholter H, Schnauder G, Muller PH, Kanduth S, Renn W. 1994. Recovery of the hypothalamicpituitary-adrenal axis from suppression by short-term, high-dose intravenous prednisolone therapy in patients with MS. Acta Neurol Scand 89: 270-273. Links

19 USP 28-NF 23. 2005. The United States Pharmacopeia - The National Formulary. Rockville, MD: The United States Pharmacopeial Convention, Inc.

20 European Directorate for the Quality of Medicines. European pharmacopoeia, 5th edition. Strasbourg, France, European Directorate for the Quality of medicines, Council of Europe, Strasbourg, France.

21 Veiga MD, Cadorniga R, Lozano R. 1985. Thermal study of prednisolone polymorphs. Thermochim Acta 96: 111115. Links

22 Kuhnert-Brandstätter M. 1977. Polymorphe und pseudopolymorphe Kristallformen von Steroidhormonen. Pharm Ind 39: 377-383. Links

23 Yang G, Ran Y, Yalkowsky SH. 2002. General solubility equation and the method using an amended salvation energy relationship. J Pharm Sci 91: 517-533. Links

24 Ran Y, Yalkowsky SH. 2001. Prediction of aqueous solubility of organic compounds by the general solubility equation (gse). J Chem Inf Comput Sci 41: 1208-1217. Links

25 Hayton WL, Guttman DE, Levy G. 1972. Effect of complex formation on drug absorption XI: Complexation of prednisone and prednisolone with dialkylpropionamides and its effect on prednisone transfer through an artificial lipoid barrier. J Pharm Sci 61: 356-361. Links

26 Sjoblom L. 1967. Pharmaceutical applications and physiological aspects of solubilisation in solvent properties of surfactant solutions. In: Shinoda K, editor. Solvent Properties of Surfactant Solutions. New York: Dekker, pp 189247.

27 Machatha SG, Yalkowsky SH. 2005. Comparison of the octanol/water partition coefficients calculated by ClogP®, ACDlogP and KowWin® to experimentally determined values. Int J Pharm 294: 185-192. Links

28 Faassen F, Kelder J, Lenders J, Onderwater R, Vromans H. 2003. Physicochemical properties and transport of steroids across Caco-2 cells. Pharm Res 20: 177-186. Links

29 Kasim NA, Whitehouse M, Ramachandran C, Bermejo M, Lennernäs H, Hussain AS, Junginger HE, Stavchansky SA, Midha KK, Shah VP, Amidon GL. 2004. Molecular properties of WHO essential drugs and provisional biopharmaceutical classification. Mol Pharm 1: 85-96. Links

30 Petereit LB, Meikle AM. 1977. Effectiveness of prednisolone during phenytoin therapy. Clin Pharmacol Ther 22 : 912-916. Links

31 Tanner A, Bochner F, Caffin J, Halliday J, Powell L. 1979. Dose dependent prednisolone kinetics. Clin Pharmacol Ther 25: 571-578. Links

$32 \mathrm{Al}-$ Habet S, Rogers HJ. 1980. Pharmacokinetics of intravenous and oral prednisolone. Br J Clin Pharmacol 10: 503-508. Links

33 Bergrem H, Grottum P, Rugstad HE. 1983. Pharmacokinetics and protein binding of prednisolone after oral and intravenous administration. Eur J Clin Pharmacol 24: 415-419. Links

34 Gambertoglio JG, Vicenti F, Feduska NJ, Birnbaum J, Salvetierra O, Amend WJC. 1980. Prednisolone disposition in cushingoid and noncushingoid kidney transplant patients. J Clin Endocrinol Metab 51: 561-565. Links

35 Frey BM, Frey FJ. 1990. Clinical pharmacokinetics of prednisone and prednisolone. Clin Pharmacokinet 19: 126146. Links

36 Täuber U, Haack D, Nieuweboer B, Kloos G, Vescei P, Wendt H. 1984. The pharmacokinetics of fluocortolone and prednisolone after intravenous and oral administration. Int J Clin Pharmacol Ther Toxicol 22: 48-55. Links

37 Frey FJ, Horber FF, Frey BM. 1988. Altered metabolism and decreased efficacy of prednisolone and prednisone in patients with hyperthyroidism. Clin Pharmacol Ther 44: 510-521. Links

38 Frey FJ, Amend WJC, Frey BM, Herford NHG, Benet LZ. 1981. Pharmacokinetics and endogenous hydrocortisone levels in cushingoid and non-cushingoid patients. Eur J Clin Pharmacol 21: 235-242. Links

39 Luippold G, Benöhr P, Schneider S, Marto M, Mühlbauer B. 2001. Bioequivalence of different prednisolone tablet formulations. Arzneim Forsch Drug Res 51: 638-642. Links 
Journal of Pharmaceutical Sciences Volume 96, Issue 1, Pages 27-37

40 Jenkins JS, Sampson PA. 1967. Conversion of cortisone to cortisol and prednisone to prednisolone. Br Med J 1: 205-207. Links

41 Powell LW, Axelson E. 1972. Corticosteroids in liver disease: Studies on the biological conversion of prednisone to prednisolone and plasma protein binding. Gut 13: 690-696. Links

42 Sullivan TJ, Hallmark MR, Sakmar E, Weidler DJ, Earhart RH, Wagner JG. 1976. Comparative bioavailability: Eight commercial prednisone tablets. J Pharmacokinet Biopharm 4: 157-172. Links

43 Tembo AV, Hallmark MR, Sakmar E, et al. 1977. Bioavailability of prednisolone tablets. J Pharmacokinet Biopharm 5: 257-270. Links

44 Rose JQ, Yurchak AM, Jusko WJ. 1981. Dose dependent pharmacokinetics of prednisone and prednisolone in man. J Pharmacokinet Biopharm 9: 389-417. Links

45 Hulme B, James VH, Rault R. 1975. Absorption of enteric and non-enteric coated prednisolone tablets. Br J Clin Pharmacol 2: 317-320. Links

46 Al-Habet S, Rogers HJ. 1989. Effect of food on the absorption and pharmacokinetics of prednisolone from entericcoated tablets. Eur J Clin Pharmacol 37: 423-426. Links

47 Prokein R. 1982. Zur Pharmakokinetik des Prednisolons: Einfluss unterschiedlicher Kostformen auf die enterale Resorption. Inaugural-Dissertation, Görich \& Weiershäuser Druck, Marburg.

48 Avdeef A, Ruell J, Du C. 2002. PAMPA structure-permeability relations of several steroids: Development of the high-throughput gastrointestinal and blood-brain barrier transport models. Available from URL: http://pioninc.com/images/GastroBBBPAMPA2002.pdf

49 Pickup ME, Lose JR, Leatham PA, Rhind VM, Wright V, Downie WW. 1977. Dose dependent pharmacokinetics of prednisolone. Eur J Clin Pharmacol 12: 213-219. Links

50 Brien TG. 1981. Human corticosteroid binding globulin. Glin Endocrinol Oxf 14: 193. Links

51 Frey FJ. 1987. Kinetics and dynamics of prednisolone. Endocr Rev 8: 453-473. Links

52 Steele WH, Hawksworth GM, Barber HE. 1982. The binding of prednisolone in human serum and to recrystallized human albumin in vitro. Br J Clin Pharmacol 14: 667. Links

53 HagerROM. 2001. Springer Verlag. Heidelberg.

54 American Academy of Pediatrics. 2001. The transfer of drugs and other chemical into human milk. Pediatrics 108: 776-789. Links

55 McKenzie SA, Selley JA, Agnew JE. 1975. Secretion of prednisolone into breast milk. Arch Dis Child 50: 894-896. Links

56 Nugent CA, Eik-nes K, Tyler FH. 1959. A comparative study of the metabolism of hydrocortisone and prednisolone. J Clin Endocrinol Metab 19: 526-534. Links

57 Hartiala J. 1976. Steroid metabolism in adult lung. Agents Actions 6: 522-526. Links

58 Szefler SJ. 1989. General pharmacology of glucocorticoids. In: Schleimer RP, Claman HN, Oronsky AL, editors. Anti-inflammatory steroid action basic and clinical aspects. San Diego, California: Academic Press, Inc, pp 353-376.

59 Loo JCK, McGilveray IJ, Jordan N, Moffat J, Brien R. 1978. Dose-dependent pharmacokinetics of prednisone and prednisolone in man. J Pharm Pharmacol 30: 736. Links

60 Legler UF, Frey FJ, Benet LZ. 1982. Prednisolone clearance at steady state in humans. J Clin Endocrinol Metab 55: 762-767. Links

61 Cheng H, Jusko WJ. 1993. Pharmacokinetics of reversible metabolic systems. Biopharm Drug Dispos 14: 721766. Links

62 Morris HG. 1978. Pharmacology and corticosteroids in asthma. In: Middleton E, Jr., Reed C, Ellis E, editors. Allergy principles and practice. St. Louis: C.V. Mosby, pp 464-480.

63 Stjernholm MR, Katz FH. 1975. Effects of diphenylhydantoin, phenobarbital, and diazepam on the metabolism of methylprednisolone and its sodium succinate. J Clin Endocrinol Metab 41: 887-893. Links 
Journal of Pharmaceutical Sciences Volume 96, Issue 1, Pages 27-37

64 Meffin PJ, Brooks PM, Sallustio BC. 1984. Alterations in prednisolone disposition as a result of time of administration, gender and dose. Br J Clin Pharmacol 17: 394-404. Links

65 Zürcher RM, Frey BM, Frey FJ. 1989. Impact of ketoconazole on the metabolism of prednisolone. Clin Pharmacol Ther 45: 366-372. Links

66 Ferry JJ, Horvath AM, Bekersky I, Heath EC, Ryan CF, Colburn WA. 1988. Relative and absolute bioavailability of prednisone and prednisolone after separate oral and intravenous doses. J Clin Pharmacol 28: 81-87. Links

67 Meffin PJ, Wing LM, Sallustio BC, et al. 1984. Alterations in prednisolone disposition as a result of oral contraceptive use and dose. Br J Clin Pharmacol 17: 655-664. Links

68 Fachinformation Decortin H $10 \mathrm{mg}$. Available from URL:

http://www.fachinfo.de/data/fi/jsearch/viewPDF?wirkstoff\&1819371871

69 Fachinformation Prednisolon-ratiopharm Tabletten. Available from URL: http://www.fachinfo.de/data/fi/jsearch/viewPDF?wirkstoff\&1988247025.

70 Fachinformation Dermosolon. Available from URL: http://www.fachinfo.de/data/fi/jsearch/viewPDF?wirkstoff\&1988246888.

71 Chulski T, Forist AA. 1958. The effects of some solid buffering agents in aqueous suspension on prednisolone. J Am Pharm Assoc (Baltim) 47: 553-555. Links

72 U.S. Department of Health and Human Services Food and Drug Administration Center for Drug Evaluation and Research (CDER). 2000. Guidance for industry: Waiver of in vivo bioavailability and bioequivalence studies for immediate-release solid oral dosage forms based on a Biopharmaceutics Classification System. Available from URL: http://www.fda.gov/cder/guidance/3618fnl.pdf.

73 Committee for Proprietary Medicinal Products (CPMP). 2001. Note for guidance on the investigation of bioavailability and bioequivalence. Available from URL: http://www.emea.eu.int/pdfs/human/ewp/140198en.pdf.

74 WHO. 2006. Multisource (generic) pharmaceutical products: Guidelines on registration requirements to establish interchangeability. Technical Report Series, No 937, 40th Report, Annex 7 of WHO Expert committee on specifications for pharmaceutical preparations. Available from URL: http://whqlibdoc.who.int/trs/WHO_TRS_937_eng.pdf.

75 Lindenberg M, Kopp S, Dressman JB. 2004. Classification of orally administered drugs on the World Health Organization Model list of Essential Medicines according to the biopharmaceutics classification system. Eur J Pharm Biopharm 58: 265-278. Links

76 Wu CY, Benet LZ. 2005. Predicting drug disposition via application of BCS: Transport/absorption/elimination interplay and development of a biopharmaceutics drug disposition classification system. Pharm Res 22: 11-23. Links

77 Amidon GL, Lennernas H, Shah VP, Crison JR. 1995. A theoretical basis for a biopharmaceutic drug classification: The correlation of in vitro drug product dissolution and in vivo bioavailability. Pharm Res 12: 413-420. Links 